\title{
Etienne Fouilloux, François Trémolières, (dirs.), Histoire et littérature chez Henri Bremond
}

Grenoble, Jérôme Millon, 2009, 218 p.

\section{Frédéric Gugelot}

\section{(Q) OpenEdition}

\section{Journals}

Édition électronique

URL : http://journals.openedition.org/assr/22028

DOI : $10.4000 /$ assr.22028

ISSN : $1777-5825$

Éditeur

Éditions de l'EHESS

Édition imprimée

Date de publication : 31 décembre 2010

Pagination : 9-242

ISBN : 9782713223013

ISSN : 0335-5985

Référence électronique

Frédéric Gugelot, «Etienne Fouilloux, François Trémolières, (dirs.), Histoire et littérature chez Henri Bremond », Archives de sciences sociales des religions [En ligne], 152 I octobre-décembre 2010, document 152-52, mis en ligne le 12 mai 2011, consulté le 21 septembre 2020. URL : http:// journals.openedition.org/assr/22028; DOI : https://doi.org/10.4000/assr.22028

Ce document a été généré automatiquement le 21 septembre 2020.

(c) Archives de sciences sociales des religions 


\title{
Etienne Fouilloux, François Trémolières, (dirs.), Histoire et littérature chez Henri Bremond
}

\author{
Grenoble, Jérôme Millon, 2009, 218 p.
}

\section{Frédéric Gugelot}

\section{RÉFÉRENCE}

Etienne Fouilloux, François Trémolières, (dirs.), Histoire et littérature chez Henri Bremond, Grenoble, Jérôme Millon, 2009, 218 p.

1 Depuis quelques années, dans la lignée des travaux d'Émile Goichot, de nombreuses études ont accompagné la réédition savante de l'Histoire littéraire du sentiment religieux. Ce colloque complète heureusement ces parutions. L'ouvrage se divise en deux parties, la première consacrée à l'écriture de Bremond et la seconde à sa réception, tant de son vivant qu'ultérieurement.

2 Il est essentiel de cerner les modes d'écriture de Bremond qui contribuèrent autant à sa reconnaissance, publique et académique, qu'aux limites de sa réception. Élaborant une troisième voie entre les études des historiens et celle des littéraires, Bremond échappe aux deux disciplines, ce qui lui ouvre un public mais lui ferme les portes de la validation universitaire. Dans sa « manière » (p. 8) de travailler, Bremond se consacre aux sources imprimées, ce qui l'éloigne des historiens de son temps très attachés aux archives, mais ouvre un territoire abandonné, la littérature dévote et spirituelle. Il n'hésite pas à œuvrer en fonction de ses empathies ou détestations, livrant un travail où le subjectif a droit d'existence sans pour autant tomber dans le piège de l'édification mêlé à une exigence d'écriture très forte sur le plan de la syntaxe et du vocabulaire.

3 Néanmoins Bremond est aussi prêtre et appartient à une institution qui oriente sa production, il est " partisan » (p. 83) dans sa lecture de Port-Royal face à Sainte-Beuve, la Réforme est absente de l'Histoire littéraire. Bremond sait surtout combien littérature 
et religion font parfois mauvais ménage et, s'il ne rompt jamais avec le camp catholique, tant dans ses oeuvres que dans sa vie, il lutte pour obtenir auprès de l'Académie française la reconnaissance refusée ailleurs. En rupture avec son ordre, tenu en méfiance par les soutiens de l'Action française, en particulier Henri Ghéon et Jacques Maritain, il parvient, en 1923, à être élu. Une fois de plus, Bremond se situe entre le clerc savant traditionnel et la figure naissante de l'écrivain catholique laïque, confronté à cette même tension entre reconnaissance publique extérieure à l'Église et nécessaire validation par cette même institution ecclésiale. La reconnaissance de l'homme de lettres lui ouvre un espace de liberté qui lui est propre.

4 Les études sur le devenir de son œuvre permettent de comprendre à la fois son succès et son estompement ultérieur. Bremond est une étape, il déplace l'attention vers des champs ignorés jusqu'à lui, les livres dévots, qu'il interprète comme une littérature de témoignage, où il se montre plus sensible à la force de l'expérience, à la volonté de rendre à tous la valeur de la sensibilité mystique, qu'à l'élaboration d'une théorie qui lui aurait permis de marquer la postérité. Il se passionne surtout pour les manières d'énoncer cette expérience indicible annonçant les travaux ultérieurs sur les «manières de dire » (p. 118).

Bremond ne s'est jamais senti proche du camp dominant alors dans le catholicisme, les maurrassiens. Tout l'éloigne de la tradition classique dont se réclame l'Action française. Celle-ci le lui rend bien en véhiculant l'image d'un abbé mondain et hypocrite qui colle à la soutane du prêtre. Si Bernanos a toujours nié que le héros de l'Imposture, l'abbé Cénabre, était la transcription littéraire de Bremond, la postérité a affirmé le contraire. L'écrivain n'hésita pourtant pas à exercer sa liberté de créateur en puisant dans le personnage Bremond les éléments évoquant l'expérience de son héros, séparé de Dieu, alors même qu'il est prêtre.

6 Ces études permettent de rendre justice à l'œuvre de Bremond, de cerner certains de ses enjeux et de ses apports et surtout d'étudier la réception et l'appropriation de l' Histoire littéraire et donc de rendre, un peu, à Bremond ce qu'il fit pour la littérature dévote et mystique du XvII ${ }^{\mathrm{e}}$ siècle. 